\title{
Role of Rydberg radicals in electrochemistry
}

\author{
Earl M. Evleth and Emil Kassab
}

Dynamiques des Interactions Moléculaires, ER 271 du C.N.R.S., Université Pierre et Marie Curie, Place Jussieu, Paris 75230

\begin{abstract}
A review is given of a relatively unknown area of the electronic structures of Rydberg radicals. The primary examples of such structures are $\mathrm{H}_{3}, \mathrm{NH}_{4}$ and $\mathrm{H}_{3} \mathrm{O}$. The condensed phase existence of the latter two has long been proposed. Mercury amalgams of organic ammonium radicals, $R_{4} N$, have been reported. Theoretical studies are reported on some of these species. An estimate is made of the relative stability of $\mathrm{NH}_{4}$ in liquid ammonia vis-à-vis $\mathrm{NH}_{4}^{+}+\mathrm{e}^{-}$.
\end{abstract}

\section{INTRODUCTION}

The role of Rydberg states in atomic and molecular photophysics and photochemistry is a specialized experimental and theoretical area (refs. 14). Ground-to-excited state Rydberg transitions are usually thought to occur in the region above $5-6 \mathrm{eV}$. Because of their extravalent characters and high energies, computations in this area are thought to be difficult. This is shown by the extreme upper state surface complexities found in even as simple a diatomic molecule as Cl, (ref. 5). However, we have demonstrated that small basis sets and a modest treatment of the correlation energy yield significant qualitative information on the photochemistry of small organic systems $\left(\mathrm{CH}_{3}, \mathrm{CH}_{4}, \mathrm{CH}_{3} \mathrm{OH}, \mathrm{CH}_{3} \mathrm{NH}_{2}, \mathrm{CH}_{2}=\mathrm{CH}_{2}\right.$, e.g. refs. 5-9).

The idea that Rydberg chemistry (refs. 1, 10) occurred only in high energy species created a conceptual mental block with regard to low energy Rydberg species until very recently. However, Herzberg pointed out in 1966 that species like $\mathrm{NH}_{4}, \mathrm{H}_{3} \mathrm{O}$ and $\mathrm{CH}_{5}$ (ref. 11) might have Rydberg ground states since the 3 s orbital would be available for bonding. He certainly knew that these species would have low lying Rydberg excited states. The basic idea is that Rydberg radicals will have low lying Rydberg excited states described by the binding interaction of an electron in a Rydberg orbital with the valence closed shell cationic core. Herzberg discovered emission from excited $\mathrm{H}_{3}$ radicals in 1979 and from $\mathrm{NH}_{4}$ shortly thereafter (for a discussion see ref. 12 ).

Herzberg's discovery of Rydberg radicals was a surprise to most theoretical chemists. Ground and excited state surface calculations of Rydberg radicals generated no extensive theoretical interest until after Herzberg's discovery (refs. 13, 14). The case of $\mathrm{H}_{3}$ is generally misleading since there is 2fold degenerate $D_{3 h}$ Jahn-Teller ground-excited state intersection and no significant local minima on the ground state surface. At the Jahn-Teller intersection the ground state is only partially Rydbergized (2p, 'E'). The fully Rydbergized first excited state has 25 character and lies less than 2 eV above the Jahn-Teller ground state intersection (ref. 13). However, in the much studied case of $\mathrm{NH}_{4}$ (ref. 14) the ground state is fully $3 \mathrm{~s}$ Rydbergized at the $\mathrm{T}_{\mathrm{d}}$ minimum. What was even more surprising was that it was found that the ground state energy of $\mathrm{NH}_{4}$ was about the same as the products of its decomposition, $\mathrm{NH}_{3}+\mathrm{H}$. An earlier theoretical study (ref $15)$ on $\mathrm{H}_{3} \mathrm{O}$ found the $3 \mathrm{~s}$ structure of the ground state of this species. However, the species was found to have such a small barrier for oH bond rupture to exoergetically ( $\mathrm{ca}$. $30 \mathrm{kcal} / \mathrm{mol}) \mathrm{yield} \mathrm{H}_{2} \mathrm{O}+\mathrm{H}$ that it was concluded that it would be difficult to ever observe such a species. Historically, theoretical computations in this area had lead to some wrong conclusions with regard to the stabilities of these kinds of species. Some work had wrongly predicted that $\mathrm{NH}_{4}$ would be unstable (ref. 16). These wrong predictions were due to the lack of inclusion of Rydberg ( $i . e$. diffuse) components in the basis set actually used in early work (ref. 17). 
It is now recognized that Rydberg radicals are qualitatively easy to compute. In any case, the idea that Rydberg states are only high energy excited species with respect to the ground state was completely destroyed with the discovery and theoretical characterization of the NH radical. However, theoretical studies on Rydberg radicals indicate that they will not be very stable but may served as intermediates in chemical reactions. These studies also indicate that in certain kinds of transition states, diffuse components should be used in the basis sets.

The next part of the Rydberg radical story occurred with the preparation of molecular beams of Rydberg radicals by porter, Gellene and coworkers (ref. 18). The method of preparations of such species in cluster forms was experimentally simple. For example, molecular beams of $\mathrm{NH}_{4}^{+}\left(\mathrm{NH}_{3}\right)$ can be easily prepared and accelerated through dilute clouds of metal atoms. Direct colisions do not occur readily at very low pressures but long distance electron transfers can. Therefore the reaction,

$$
\mathrm{NH}_{4}{ }^{+}\left(\mathrm{NH}_{3}\right)_{\mathrm{n}+\mathrm{m}}+\mathrm{Na}=\mathrm{NH}_{4}\left(\mathrm{NH}_{3}\right)_{\mathrm{n}}+\mathrm{m}\left(\mathrm{NH}_{3}\right)+\mathrm{Na}+
$$

can occur. Neither uncomplexed $\mathrm{NH}_{4}$ nor $\mathrm{H}_{3} \mathrm{O}$ have been detected but their deuterated counterparts have. It has been concluded (ref. 14,18) that the ND and $O D$ bond rupture activation energies are only several $\mathrm{kcal} / \mathrm{mole}$. Therefore, both zero point energy effects and reduced tunneling play a role in stabilizing $\mathrm{ND}_{4}$ and $\mathrm{D}_{3} \mathrm{O}$. However, $\mathrm{NH}_{3}$ complexed forms of $\mathrm{NH}_{4}$ have long beam lifetimes. Attempts to prepare organic Rydberg radicals (e.g. $\mathrm{CH}_{5}$ ) have not yet been successful nor as equally well explored. Our discussion below will allow one to estimate stability of Rydberg radicals and rationalize the kinetic barrier for bond rupture.

Rydberg radicals have some relevance to interstellar chemistry since electron-cation dissociative recombination,

$$
A B^{+}+e^{-}=\left(A B^{*}\right)=A+B
$$

is an important processes in ion-molecule chemistry. Our goal here is to theoretically speculate on the possible role of Rydberg radicals as metastable intermediates in condensed phase chemistry formed by a similar process, either by the capture of a solvated electron or at an electrode surface. It turns out that organic ammonium radicals, $R_{4} N$, have been known much longer than the above discussion would indicate. poorly characterized mercury amalgams, formed by the electron reduction of tertiary ammonium salts at mercury surfaces, have been known since the beginning of this century (refs. 19,20). The possible existence of $\mathrm{NH}_{4}$ and $\mathrm{H}_{3} \mathrm{O}$ radicals in electrochemistry and in the reactions of the solvated electron has been speculated on for a number of years (ref. 21). The major questions are: what are the structures of these amalgams? Do isolated organic ammonium radicals have any stability? What is the role of these kinds of radicals in electrochemistry, in the reaction of the solvated electron?. We will address some of these points with a theoretical description of the properties of $\mathrm{NH}_{4}$ and related structures.

\section{SOME COMMENTS ON COMPUTING RYDBERG RADICALS}

The ground and lowest excited states of Rydberg radicals can be computed using a standard valence basis set supplemented by the diffuse components necessary to describe the Rydberg character of the structures under investigation. Although spectroscopic accuracy will require large basis sets, significant chemical information can be obtained at the $D 2+3 s, p$ level in the case of $\mathrm{NH}_{4}$. Since the $\mathrm{NH}$ radical ground state has a simple electronic structure, qualitatively described as ( $\left.\mathrm{NH}_{4}^{+}\right)\left(\mathrm{e}^{-}\right)_{3}$, it can be treated at single configuration RHF or UHF open shell level. subsequent correlation corrections can be done using Moller-Plesset (MP) perturbation or CI methods. A single parent configuration will dominate the MP or CI expansion for the ground state minima. The treatment of the reaction surfaces is more complicated. The ground state surface for the reaction:

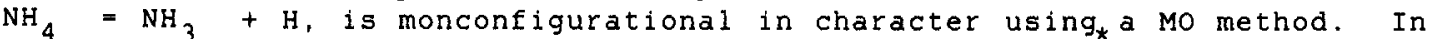
this case, the highest half-filled MO will have $35 \sigma^{*}$ character, the approximate functional form being: $c_{1}(3 s)+c_{2}(1 s H)$. At the $T$ geometry, the $3 \mathrm{~s}$ part of the function dominates. At large $\mathrm{NH}$ distances the function is dominated by the $1 \mathrm{sH}$ component. At intermediate $\mathrm{NH}$ distances $\mathbf{s} 0 \mathrm{me} \mathrm{NH}_{3}$ antibonding components will also be mixed in. The 3so* designation implies bonding in Rydberg space and antibonding in valence space. This behavior can be reformulated in at the state level using a vB-type structural 


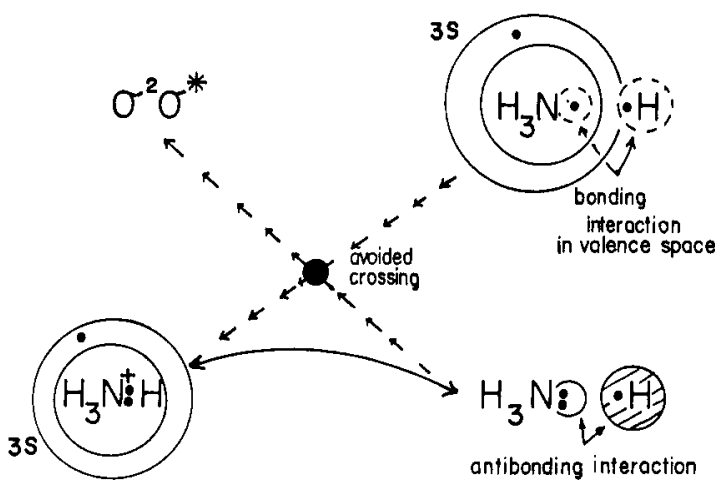

Figure 1. Structural correlation diagram explaining the behavior of the ground and first excited state surface for $\mathrm{NH}$ bond rupture in the $\mathrm{NH}_{4} \mathrm{Radical}$ (see ref.l4e for the correlations of the excited states).

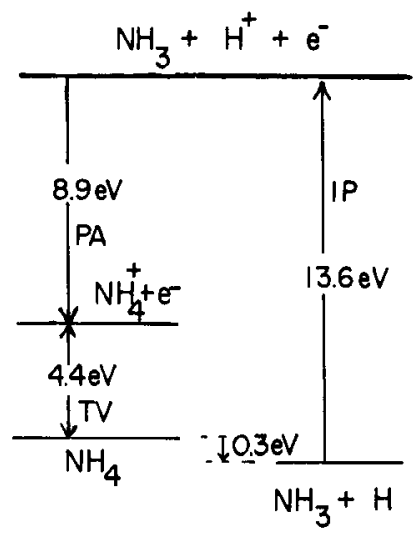

Figure 2. A thermospectroscopic estimation of the stability of $\mathrm{NH}_{4}$ vis-a-vis $\mathrm{NH}_{3}+\mathrm{H}$.

correlation diagram (Fig. 1). The theoretical origins of the stability and electronic structure of $\mathrm{NH}_{4}$ are due to its structural correlation with the first excited (Rydberg) state of $\mathrm{NH}_{3}+\mathrm{H}$. The first excited state of $\mathrm{NH}_{3}$ is described by the excitation of one of the non-bonding electrons from an norbital to a $3 \mathrm{~s}$ Rydberg orbital as structurally shown in $\mathrm{Fig}$. 1 . In $\mathrm{n}, 3 \mathrm{~s}$ excited $\mathrm{NH}_{3}$ the half-filled n-orbital is available for $\sigma(\mathrm{NH})$-bond formation with the $\mathrm{H}^{3}$ atom. Therefore, the excited state interaction of $\mathrm{NH}_{3}+\mathrm{H}$ is bonding. However, in the ground state of $\mathrm{NH}_{3}+\mathrm{H}$, there is a antibonding interaction due to three electrons occupying the same symmetry $\sigma$ space. In Mo terms this 3-electron configuration is described as a $\sigma^{2} \sigma^{*}$ interaction. If one were to perform a calculation without Rydberg components (i.e. ref. 16) only a repulsive $\mathrm{NH}$ surface would be obtained for an $\mathrm{H}$ atom approaching the filled n-orbital of $\mathrm{NH}_{3}$. However, with a 3s-Rydberg component, the ground state surface VB-like wavefunction can be expressed in a simple two configurational form: $c_{1}\left(\sigma^{2} \sigma^{*}\right)+c_{2}\left(\mathrm{NH}_{3}{ }^{+}, 1 \mathrm{sH}\right)(3 \mathrm{~s})$. The latter term becomes a $\mathrm{NH}$ bond in valence space as the lsH orbital couples to the $\mathrm{NH}_{3}+$ component. As shown in Fig. 1 , the ground state behavior results from an avoided crossing of VB-type frozen configurations. However, in MO-CI terms, this surface form can also be expressed in single configurational terms as an evolution of only the $\sigma^{*}$ Mo. The advantage of the structural correlation diagram is that one anticipates a surface barrier in passing from $\mathrm{NH}_{4}$ to $\mathrm{NH}_{3}$ + H. At the maximum of this barrier one expects about $50-50$ mixed Rydbergvalence character as the wavefunction evolves from being fully Rydberg at $\mathrm{NH}_{4}$ to fully valence at $\mathrm{NH}_{3}+\mathrm{H}$. The calculations show this behavior.

The reasons for the near isoergicity of $\mathrm{NH}_{4}$ and $\mathrm{NH}_{3}+\mathrm{H}$ on the ground states surface can be rationalized using the thermospectroscopic cycle shown in Fig. 2. Of the three energies necessary to construct this cycle, the ionization potential (IP) of the H-atom and the proton affinity of $\mathrm{NH}_{3}$ (PA) are known experimentaliy. The IP for the $\mathrm{NH}_{4}$ radical can be assumed to be close to the term value (TV) for the lowest excited state of NH (ref. 4). Using these numbers, the reaction $\mathrm{NH}_{4}=\mathrm{NH}_{3}+\mathrm{H}$ is 0.3 eV exoergic. $\mathrm{Ab}$ initio calculations show a value near zero. The work of porter et al. (ref. 18) is in accord with these estimates as are the direct calculations (ref. 14). Fig. 2 demonstrates that one can make reasonable estimates of the thermodynamic stabilities of Rydberg radicals without direct computations. Experimental information on the IP, PA, and TV will be sufficient to make a reasonable first order guess.

\section{COMPLEXATION OF $\mathrm{NH}_{4}$ RADICAL WITH $\mathrm{NH}_{3}$ IN CLUSTERS AND LIQUID $\mathrm{NH}_{3}$}

Since the $\mathrm{NH}_{4}$ radical ground state is descriptively an electron in a $3 \mathrm{~s}$ orbital bound to an $\mathrm{NH}^{+}$core, the complexation of the $\mathrm{NH}_{4}$ with $\mathrm{NH}_{3}$ will be partially ionic in character. Figure 3 shows the variation of the scaled ab initio complexation energies with cluster size (ref. 14e) for both the neutral and cationic species. For $\mathrm{n}=1$, the complexation energy of $\mathrm{NH}_{4}$ with $\mathrm{NH}_{3}$ is $1.08 \mathrm{eV}$, for the Rydberg radical, $0.42 \mathrm{eV}$. For neutral $\mathrm{NH}_{3}$ with itself, the experimental value is about $0.25 \mathrm{ev}$. As the size of the 


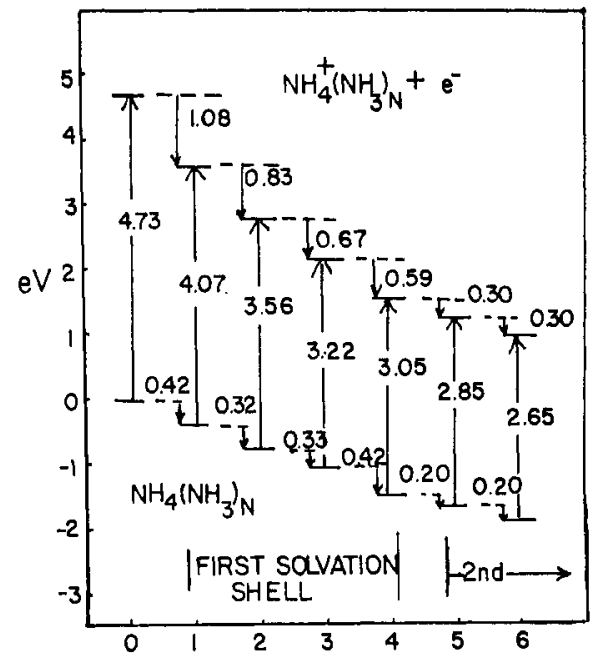

Figure 3. Scaled ab initio complexation energies of both $\mathrm{NH}_{4}^{+}$and $\mathrm{NH}_{4}$ with $\mathrm{NH}_{3}$ (from ref. I4e).

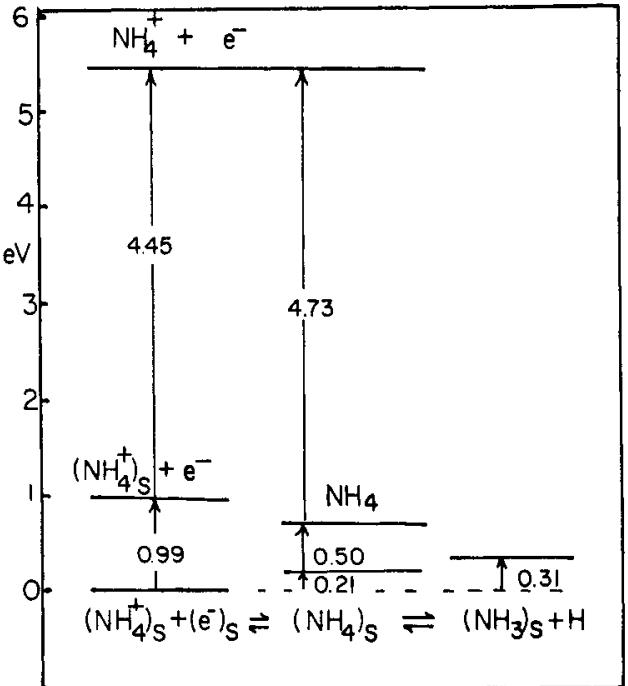

FIGURE 4. Estimate relative energies of $\mathrm{NH}_{4}^{+}, \mathrm{NH}_{4}$ and the electron in the gas phase and liquid $\mathrm{NH}_{3}$.

$\mathrm{NH}_{4}\left(\mathrm{NH}_{3}\right)$ cluster increases beyond the first solvation shell $(n>4)$, the extrabonaing of $\mathrm{NH}_{3}$ units onto an existing Ryaberg cluster does not exceed the bonding of $\mathrm{NH}_{3}$ with itself. As seen from Figure 3 , the IP of $\mathrm{NH}_{4}$ in $\mathrm{NH}_{3}$ clusters gradually decreases. Since the solvation energy of ( $e^{\text {) }}$ in liquid $\mathrm{NH}_{3}$ (ref. 22) is $0.99 \mathrm{eV}$, one can predict that the IP of $\mathrm{NH}_{4}$ in liquid $\mathrm{NH}_{3}$ would not be more than $2 \mathrm{eV}$. However, using the estimated solvation energy of $\mathrm{NH}^{+}$in $1 \mathrm{iq.} \mathrm{NH}_{3}$ (ref. 22), $4.45 \mathrm{eV}$, as well as the gas phase IP of $\mathrm{NH}$ (ref. $\left.{ }^{4} 18\right), 4.73 \mathrm{eV}^{3}$ one can estimate that $\mathrm{NH}_{4}$ in the gas phase is only 0.71 eV higher in energy than $\left(\mathrm{NH}_{4}{ }^{+}\right)+\left(e^{-}\right)_{s}$ in lig. $\mathrm{NH}_{3}(\mathrm{Fig} .4)$. In order to estimate the energy of $\mathrm{NH}_{4}$ in $\mathrm{IIq}$. $\mathrm{NH}_{3}$ sone needs to estimate the solvation energy of $\mathrm{NH}^{4}$. Figure 3 indicates ${ }^{3}$ that this solvation energy is much greater (several eV) than $\mathrm{NH}_{3}$ with itself $(0.25 \mathrm{eV}$ ). The total computed energy for forming the first solvation shell complex $(n=4)$ is $-1.50 \mathrm{eV}$. However, in forming this species, one has to remove $4 \mathrm{NH}_{3}$ from liq. $\mathrm{NH}_{3}$ $(4 \times 0.25 \mathrm{ev}=1.00 \mathrm{eV})$. Therefore, if $\mathrm{NH}_{4}\left(\mathrm{NH}_{3}\right)_{4}$ has no additional solvation energy in liq $\mathrm{NH}_{3}$, the solvation energy of $\mathrm{NH}_{4} 4$ would be $0.50 \mathrm{eV}$ (i.e. -1.50 $+1.00)$. Figure 4 shows this solvation energy and places $\left(\mathrm{NH}_{4}\right)_{5}$ intermediate in energy between $\left(\mathrm{NH}_{4}{ }^{+}\right)_{\mathrm{s}}+\left(\mathrm{e}^{-}\right)_{\mathrm{s}}$ and $\left(\mathrm{NH}_{3}\right)_{\mathrm{g}}+\mathrm{H}$ (refs. $\left.14 \mathrm{e}, 22\right)$. Figure 3 shows that the solvation energy of $\mathrm{NH}_{4}$ might even be higher than this value. However, we have argued (ref. Ife) that due to the bubble structure that Rydberg states must have in condensed media, the solvation energy of $\mathrm{NH}$ in liq. $\mathrm{NH}_{3} \mathrm{can}$ not exceed $0.5 \mathrm{eV}$. It is the requirement for a bubble structure which differentiates the solvation of Rydberg species from ordinary valence species.

\section{BUBBLE STATE STRUCTURES OF RYDBERG STATES IN CONDENSED MEDIA}

For Rydberg species, an electron in a Rydberg orbital is moving in a spatial region where, in general, the valence electrons are not. The average electron densities of a 3 s Rydberg orbital are in the order of 100 times less than in valence space. The maximum of the Rydberg electron density lies outside the valence Van der Waals radil of the molecule. If another molecule should enter into the Rydberg space, the Rydberg electron will also avoid this intruder's valence space. This simple model also suggests that the intruder will also be repulsed. However, this is not always the case if sufficient non-intruded space exists for the Rydberg electron to move in and there is an overpowering interaction in valence space between the intruder and parent's cationic core. In fact, as we have seen in Fig. 1 the interaction between an excited Rydberg species and an atom may be large. In addition, Rydberg bimolecular reactions sometimes strongly mimic ionmolecule reactions (for additional discussion see refs. 1 , l4e). One sees here exoergic stepwise complexation energies for the $\mathrm{NH}_{4}\left(\mathrm{NH}_{3}\right)_{\mathrm{n}}$ clusters up to $n=6$. However, calculations placing either $6 \mathrm{H}^{4}$ or 6 He atoms symmetrically around $n, 3 s$ excited $\mathrm{NH}$ show strongly repulsive interactions 


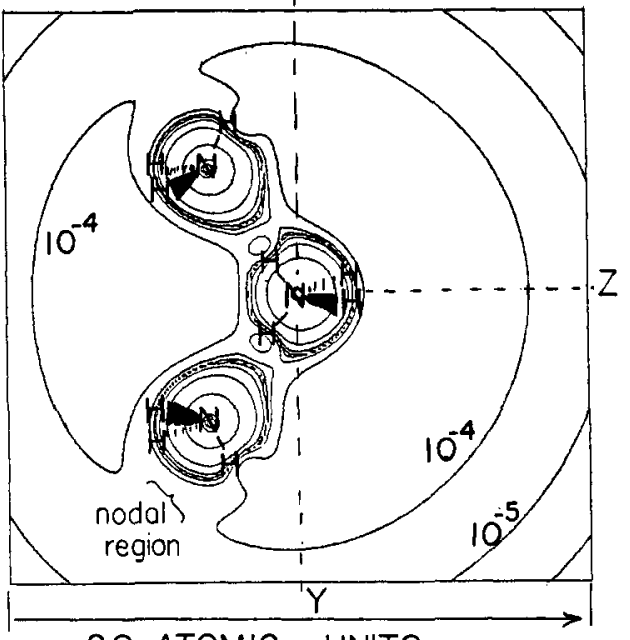

20 ATOMIC UNITS

Figure 5. Electron density map of the $3 \mathbf{s}$ orbital in the complex $\mathrm{NH}_{4}\left(\mathrm{NH}_{3}\right)_{2}$ in the $x z C_{2 v}$ symmetry plane. Density units in electrons per cubic atomic unit. Note the nodal valence region avoided by the Rydberg electron.

(ca. $1 \mathrm{eV}$ ) at the ground state vertizal excitation geometry. In this case the intruders are repulsed to beyond $5 \AA$. Therefore, intruders which can not interact in some bonding manner with a Rydberg species will be repulsed. In condensed media, in order to maintain a Rydberg species, a bubble will have to be constructed to house the Rydberg electron. In Figure 5 is shown, for the $\mathrm{NH}_{4}\left(\mathrm{NH}_{3}\right)$ cluster, the 35 orbital electron
density. The maximum of Rydberg electron density 1 ies within the $10^{-4}$ electrons/au region. This is outside the valence space of the cluster.

The shown nodal region is the valence space of the molecule, which although containing some electron density is low on an integrated scale. The $\mathrm{NH}_{4}\left(\mathrm{NH}_{3}\right)_{4}$ cluster also shows $3 \mathrm{~s}$ electron density lying between the complexing $\mathrm{NH}_{3}$ units. For the $\mathrm{NH}_{4}\left(\mathrm{NH}_{3}\right)_{6}$ cluster, in which two $\mathrm{NH}_{3}$ units themselves are themselves complexed, the 3 s density is pushed out around the uncomplexed $\mathrm{NH}_{3}$ units. Technically, calculations at larger clusters were yet not possible. Our assumption is that endoergic stepwise complexation energies would be encountered at the $n=7,8$ and larger clusters. Our suggested optimum model for $\mathrm{NH}_{4}$ in 1 iq. $\mathrm{NH}_{3}$ is the $\mathrm{NH}_{4}\left(\mathrm{NH}_{3}\right)_{4}$ cluster in which additional $\mathrm{NH}_{3}$ units are repulsed beyond the $5 i \mathrm{se}^{4}$ the Rydberg orbital. This structure would allow taking advantage of its $-1.50 \mathrm{eV}$ complexation energy. In this case the bubble would be created around the $\mathrm{NH}_{4}\left(\mathrm{NH}_{3}\right)_{4}$ structure in which no additional $\mathrm{NH}_{3}$ solvent molecules could approach for additional binding.

\section{COMMENTS ON THE STABILITY OF ORGANIC AMMONIUM RADICALS AND RELATED STRUCTURES}

The instability of $\mathrm{NH}_{4}$ radical under isolated conditions is in contrast with the stability of alkyl ammonium radicals, $R_{4} N$, in amalgam forms. The composition of these amalgams, $c a . R_{4} N(H g){ }_{2}$, is not really known. But the amalgams are stable at $0^{\circ} \mathrm{C}$. We have performed (ref. l4e) calculations on the $\mathrm{C}-\mathrm{N}$ rupture surfaces for: $\left(\mathrm{CH}_{3}\right)_{4} \mathrm{~N}=\left(\mathrm{CH}_{3}\right)_{3} \mathrm{~N}+\mathrm{CH}_{3}$. We concluded that the activation energy for this reaction would ${ }^{3} \mathrm{le}_{\mathrm{e}}$ below $10 \mathrm{kcal} / \mathrm{mol}$. If so, isolated $\left(\mathrm{CH}_{3}\right) \mathrm{N}$ species would have kinetic lifetimes much shorter than observed in the amalgams. Our conclusion is that the stabilities of the ammonium radical amalgams are due to delocalization or deRydbergization of the organic species on complexation with ( $\mathrm{Hg})$. One can generally envisage metallic-like bonding between Rydberg radicals and other electron sharing species. The complicating feature is that other reaction channels may exist In the case of $\mathrm{NH}_{4}$ dimer ( $\mathrm{Na}_{2}-\mathrm{like}$ ), we found a low MCSCF activation energy to yielding $2 \mathrm{NH}_{3}+\mathrm{H}_{2}$ (ref. 23 ).

Finally we should mentioned that the electron affinities of -NR ${ }^{+}$units will be in the $4 \mathrm{eV}$ region as found for $\mathrm{NH}_{4}$. Therefore, one should not automatically assume that the zwitterionic forms should be the ground states in structures containing, for example, both $-\mathrm{NR}_{3}{ }^{+}$and negatively charged moeities. Diradical ground state structures may be encountered in special structural situations. Computational verification of which is the most stable structure will require either an MCSCF technique or CI determination of the relative ground and lower excited state energies. 
Acknowledgements The computations reported here were performed at the C.N.R.S.C.I.R.C.E. computing center at orsay, France. We thank the staff for their generous aid.

\section{REFERENCES}

1. E. M. Evleth and E. Kassab, "Rydberg Chemistry", in Unconventional Chemical Bounding eds. J. Liebman and A. Greenberg, VCH NY, in press.

2. Photophysics and Photochemistry in the Vacuum Ultraviolet, eds. S. P. McGlynn, G. L. Findley, R. H. Huebner, Reidel, Dordrecht (1982).

3. Photophysics and Photochemistry above $6 \mathrm{eV}$, ed, F. Lahmani, Elsevier, Amsterdam, (1985).

4. M. B. Robin, Higher Excited States of Polyatomic Molecules, Academic Press, New York, vol. 1 (1974), vol 2 (1975).

5. S. D. Peyerimhoff and R. J. Buenker, Chem. Phys. 57, 279-296 (1981).

6. E. M. Evleth, H. Z. Cao and E. Kassab, ref. 3, 479-495.

7. E. Kassab, G. T. Gleghorn, and E. M. Evleth, J. Am. Chem. Soc. 105, 1746-1753 (1983).

8. H. T. Yu, A. Sevin, E. Kassab, E. M. Evleth, J.Chem. Phys. 80 , 20492059 (1984), erratum, ibid, 8i, $1519(1984)$.

9. E. M. Evleth and A. Sevin, J. Am Chem. Soc. 103, 7414-7422 (1981).

10. C. Sandorfy, Top. Current Chem. 86, 91-138 (1979).

11. G. Herzberg, Molecular Spectra and Molecular. Structure, Van Nostrand, Princeton, N. J., 3, 397 (1966).

12. G. Herzberg, Faraday Discuss. Chem. Soc. 71, 163-173 (1981).

13. (a) H. F. King and K. Morokuma, J. Chem. Phys. 71, 3213-3219 (1979).

(b) M. Jungen, ibid, 71,3540 (1979). (c) R. L. Martin, 卢id, 71, 3541 (1979).

14. (a) S. Raynor and D. A. Herschbach, J. Phys. Chem. $86,3592-3598$ (1982) (b) E. Broclawik, J. Mrozek, and V. H., Smith,Jr., Chem. Phys. 66, 417$423(1982)$. (C) H. Cardy, D. Liotard, A. Dargelos, and E. Poquet, Chem. Phys. 77, 287-299.(1983). (C) S. Havriliak and H. F. King, J. Am. Chem. Sog. $\overline{105}, 4-12(1983)$. (d) J. Kaspar, V. H. Smith, ir., and B. N. McMaster, Chem. Phys. 96, 81-95 (1985). (e) E. Kassab and E. M. Evleth, J.Am.Chem. Soc. 109, 1653-1661 (1987).

15. K. S. E. Niblaeux, N. O. Roos, and E. M. Siegbahn, Chem. Phys. 25, $207-213(1977)$.

16. (a) W.A. Lathan, W.J. Hehre, L.A. Curtis, J.A. Pople, J. Am. Chem. Soc. 93, 6377-6387 (1971). (b) M.S. Gordon, D.R. Gano, ande J.A. Boatz, J. Am. Chem. Soc. 105, 5771-5775.(1983).

17. (a) C.E. Melton and H.W. Joy, J. Chem. Phys. 46, 4275-4283 (1967). (b) w. Strehl, H.K. Hartman, B. Heñsen, and W. Sarholz. Theoret. Chem. Acta 18, $290-308(1970)$.

18. (a) G.I. Gellene, and R.F. Porter, J. Phys. Chem. 88, 680-6684 (1984). (b) S. Jeon, J. A. B. Raksit, G. I. Gellene, and R. F. Porter, J. Am. Chem. Soc. 107, 4129-4133(1985). (C) G.I. Gellene and R.F. Porter, J. Chem. Phys. 81, 5570-5576.(1984) (d) G.I. Gellene, D.A. Cleary, and R.F. Porter, J. Chem. Phys. 77, 3471-3477(1982). (e) G. I. Gellene and R. F. Porter, Acts.Chem. Res. 16, 200-207 (1983). (f) B.W. Williams and R. F. Porter, J. Chem. Phys. 73, 5598-5604, (1980).

19. J.K.S. Wan, J. Chem. Ed. 45, 40-43 (1968).

20. E. Kariv-Miller, C. Nanjundiah, J. Eaton, and K.E.J. Swenson, Electroanal. Chem. 167, 141-155 (1984),. (C) J.D. Littlehailes and B. J. Woodhall, Faraday Discuss. Chem. Soc. 45 187-192 (1968).

21. (a) M. Anbar, Solvated Electron, Ad. Chem. Ser., 50, 55-81 (1965). (b) L. Horner, organic Electrochemistry ed. M.M. Baizer, Marcel 429-443, Deckker. NY. (1973). (c) J.M. Brooks and R.R. Dewald, J. Phys. Chem. 75, 986-987 (1971). (d) O.R. Bron Electrochemistry Spec. Report Chem. Soc. 4, 55-77 (1974). (e) R.K. Quinn, and J.J. Lagowski, J. Phys. Chem. 72, $1374-1378$ (1968). (f) J.L. Dye, M.G. DeBacker, ard L.M. Dorfman, J.Chem. Phys. 52, 6251-6258. (1970). (g) H.A. Laitinen, and C.J. Nyman, J. Phys. Chem. $\frac{70}{45}, 3002-3008$ (1948). (h) R.N. Gedye, and Y.N. Sadana, J. Org. Chem. $\overline{45}, 3721-3722 .(1980)$.

22. (a) U. Schindewolf, Ber. Bunsenge. Phys. Chem. 86, 887-894 (1982).

(b) U. Schindewolf, J. Phys. Chem. $88,3820-382 \frac{86}{6}$ (1984).

23. E. Kassab, J. Fouquet, and E. M. Evleth, in preparation. 